\title{
FREUD E SARTRE: DA DETERMINAÇÃO PULSIONAL À RESPONSABILIDADE
}

\author{
Luciene Braga Ramos Borges1; Malcom Guimarães Rodrigues2
}

\author{
1: Bolsista FAPESB, Graduanda da Licenciatura em Filosofia, \\ Universidade Estadual de Feira de Santana, e-mail: luci eneramos@hotmail.com \\ 2: Orientador: Dr. Malcom Guimarães Rodrigues, Departamento de Ciências \\ Humanas e Filosofia, Universidade Estadual de Feira de Santana, e-mail: malcomgr@gmail.com
}

PALAVRAS-CHAVE: Determinismo psíquico; Pulsão de morte; Responsabilidade

\section{INTRODUÇÃO}

Na obra Além do princípio de prazer (1920/2010a), Freud introduz nas teorias psicanalíticas o conceito de pulsão de morte, como presente no processo vital interagindo como uma força em conflito dentro de um quadro psíquico mais amplo, no qual as explicações das ações humanas eram procuradas. Introduzir este conceito era uma tentativa de responder, entre outras, a questão: por que algumas ações ou pensamentos característicos do comportamento humano, pensando este em relação à questão das neuroses traumáticas, por exemplo, não obedecem ao "princípio de prazer"? A observação clínica levou Freud (1930/2010b) a perceber certos comportamentos como: compulsão a repetição do desprazer; sentimento de culpa e necessidade de punição, como demonstrativos deste tipo de análise, decorrendo daí a necessidade de rever suas teorias. Levando em consideração que o "princípio de prazer" era, até então, considerado por Freud (1900/2001) como aquele que rege o aparelho psíquico na sua tendência a um menor grau de excitação possível que tenderia ao prazer e, partindo desta perspectiva, questionamos: o que explicaria a repetição de movimentos dolorosos como consequência de um aumento de excitabilidade e, portanto, a aparente escolha por um quadro de sofrimento? Para Freud parece que essa escolha não é feita de modo plenamente consciente, enquanto para Sartre (1943/2014b) não pode ser imputada a um inconsciente. Sartre (1943/2014b) não ignora que as escolhas da realidade humana frequentemente constituem um mundo de sofrimento, no entanto a responsabilidade por esse tipo de ação contraditória pode ser creditada a realidade humana e não estaria relacionada a elementos pulsionais conforme afirma Freud.

Enquanto para Freud (1900/2001, p. 523), as ações dos homens devem ser analisadas levando-se em consideração os impulsos inconscientes que irrompem na consciência, mesmo que muitas vezes eles sejam neutralizados pelas forças reais da vida, Sartre (1943/2014b) contesta decisões fundamentadas em um "eu" interior, que se sustente na noção de inconsciente e atribui a realidade humana plena liberdade para fazer escolhas responsáveis, indo de encontro a noção de aparelho psíquico regido por pulsões, implícito nas teorias freudianas.

\section{MATERIAL, MÉTODOS OU METODOLOGIA (ou equivalente)}

Os materiais utilizados foram prioritariamente de ordem textual: livros, artigos, textos etc. A metodologia consistiu, basicamente, em leituras, fichamentos, análises textuais e produção de textos. Os encontros com o orientador e a participação nos grupos de estudo e pesquisa foram fundamentais, especialmente no início da pesquisa, momento no qual as primeiras leituras foram discriminadas e analisadas. Depois das primeiras leituras e fichamentos, a partir dos encontros com o orientador, passamos à produção do primeiro relatório. Com o avanço da pesquisa, fez parte da metodologia a produção de textos para eventual publicação e a participação em eventos para apresentação dos resultados parciais e/ou finais da pesquisa. Por último, passamos a produção do relatório final e preparação para apresentação dos resultados encontrados no SEMIC - 2016. 


\section{RESULTADOS E/OU DISCUSSÃO (ou análise e discussão dos resultados)}

Ao longo das pesquisas percebemos que se tratando das ações da realidade humana Sartre afirma, na obra A transcendência do Ego (1934/2013), que tanto as ações objetivas, no sentido de ações tomadas no mundo das coisas, como escrever, andar, tocar piano, quanto ações psíquicas como duvidar, raciocinar, fazer hipóteses são entendidas como uma realidade concreta e não resultados de causalidades interna que estejam fundamentadas em um inconsciente. Sartre (2013, p.53) não rejeita a parte da psicanálise cujos resultados são obtidos pela compreensão, ele nega apenas, como ele mesmo diz, o valor e a inteligibilidade das teorias psicanalíticas subjacentes da causalidade psíquica. $\mathrm{O}$ erro freudiano, segundo ele, foi defender a tese de que os pensamentos brotam de um inconsciente impessoal que se tornam "personalizados" ao tornar-se consciente,

Ela (tese) tem sido sustentada por psicólogos que compreenderam muito bem que a consciência não "saía" do Eu, mas que não eram capazes de aceitar a ideia de uma espontaneidade que se produzisse a si mesma. Esses psicólogos, portanto, imaginaram ingenuamente que as consciências espontâneas "saíam" do inconsciente onde já existiam, sem perceber que tinham apenas feito retroceder o problema da existência, que afinal precisa ser formulado, e que o haviam obscurecido, pois a existência anterior das espontaneidades nos limites pré-conscientes seria necessariamente uma existência passiva. (SARTRE, 2013, p.72) $)^{1}$

Para a presente pesquisa, que questiona se para Sartre as ações que emanam de uma liberdade absoluta - no que concerne especificamente às escolhas pela dor, sofrimento ou infelicidade - poderiam ter relação com elementos pulsionais, especialmente com a ideia de pulsão de morte e, se poderiam ser imputadas a um inconsciente, entendemos que Sartre não aceita a postura psicanalítica que afirma que as ações estão fundamentadas em um desejo psíquico inconsciente porque ele nega a ideia de um inconsciente a partir da própria ideia de consciência. A consciência é, por princípio, "consciência de alguma coisa" (SARTRE, 2014a, p.682). Para ele o ponto de partida da filosofia seria expulsar as coisas da consciência, purificá-la do "Eu", restabelecendo a verdadeira relação entre ela e o mundo: "a consciência como consciência posicional do mundo" (SARTRE, 2014a, p. 22).

A realidade humana, nesta concepção sartriana, vai na contramão do sujeito freudiano, mesmo que, em princípio, admita que esta realidade humana "anuncia-se e se define pelos fins a que persegue" (SARTRE, 2014a, p.682) o que também implica uma forma de desejo; mesmo que admita uma inspiração na psicanálise freudiana ao elaborar a sua "Psicanálise Existencial" e estruturar a sua tese sobre a finalidade da realidade humana em si mesma. ${ }^{2}$

\section{CONCLUSÃO E/OU CONSIDERAÇOES FINAIS.}

Para Sartre (2014a, p. 540), a consciência tem a possibilidade de efetuar uma ruptura com um passado infeliz, mas o contrário disto, ou seja, o passado ter força de, por si mesmo produzir um ato, o que parece indicar as teorias de Freud, ele não aceita. Quem confere o valor de motivo é a própria realidade humana e em estreita relação com o futuro, entendido como projetar, como fins a serem alcançados ou algo posicionado idealmente, como, por exemplo, escolher pela vida como um projeto fundamental. A questão não parece ser simplesmente afirmar se há ou não há motivos para

\footnotetext{
${ }^{1}$ Sartre (2013, p.79), em contrapartida, defende uma consciência absoluta, purificada do Eu, que nada mais tem do sujeito, nem é resultado de uma coleção de representações, mas é "uma condição primeira e uma fonte absoluta de existência" (SARTRE, 2013, p.79). Quanto a distinção entre consciência ativa e espontânea, ele considera um dos problemas mais difíceis de se resolver na fenomenologia. Cf. Sartre, 2013, p. 50.

${ }^{2}$ Sobre o tema aproximações e divergências entre a psicanálise freudiana e a psicanálise existencial, de Sartre, pesquisar em O Ser e o Nada (1943/2014a), capítulo 2 - Fazer e Ter - A psicanálise existencial, pp. 682-703.
} 
escolha "pelo sofrimento" como atos, pois para Sartre (2014a, p. 541) há os motivos, mas não como causas, como determinantes de ações, como se um gesto de levantar a mão, por exemplo, estivesse implicado, necessariamente, a motivos que remetem a uma significação. Ele diz que isso é simplificar demais a questão. Contudo, para ele há algo claro, é que "a realidade humana não poderia receber seus fins, nem de fora, nem de uma pretensa natureza interior. Ela os escolhe e, por essa mesma escolha, confere-lhes uma existência transcendente como limites externos de seus projetos" (SARTRE, 2014a, p. 548). Tudo remetendo ao posicionamento dos fins. Estes estão posicionados por uma escolha antes de qualquer reflexão, pois esta reflexão se daria em um segundo momento. Por isso a todo instante a realidade humana se escolhe, da maneira como vai conduzir-se, em relação aos fins, e até que atitudes tomar em um determinado momento.

Sartre (2014a, p. 549) não admite que circunstâncias externas ou internas determinem as escolhas, sejam elas quais forem, pois suprimiria a liberdade, no entanto parece que ele está nos remetendo a um outro tipo de escolha, que não seja aquilo que entendemos comumente como escolha pressupondo algo refletido. Ele recusa o acaso determinista de Freud e diz que em lugar de tentar compreender o fenômeno, seja ele qual for, a partir do passado, vai conceber o ato compreensivo como um retorno do futuro que se realiza no presente. As ações não são efeitos de estados psíquicos anteriores, fazem parte de uma estrutura, de um projeto, de uma totalidade que é a realidade humana como liberdade. O que permite evitar o erro do inconsciente, de Freud, é que estes atos não se distinguem da escolha de si mesmo da realidade humana dentro do mundo, mesmo que esta escolha seja não deliberada. Sartre (2014a, p. 569) afirma em relação a isto que uma consciência de escolha é idêntica a uma consciência que temos de nós e é por isso temos consciência de quem nós somos quando escolhemos. É o que Sartre (2014a, p. 573) chama de escolha original. ${ }^{3}$ Compreendê-la' é já ter escolhido antes. Portanto, a discussão sobre escolhas pelo sofrimento não perpassa o âmbito do consciente e inconsciente, como Freud aponta nas suas teorias para explicar as escolhas deste tipo, que poderiam ser explicadas em algum momento a partir do conceito de pulsão de morte ou da renúncias às pulsões, por exemplo. Sartre não se utiliza dos mesmos parâmetros que Freud usa para falar de ações, ou seja, que as condutas tem como base a obscuridade de um inconsciente. Se Freud tenta explicar o mal-estar da nossa civilização recorrendo ao que ele entende como renúncias de impulsos inconscientes - da destrutividade externa, a pulsão de morte - Sartre (2010, p. 54), em contrapartida, vem afirmar que as escolhas não são feitas tendo como pano de fundo uma causa interna, o que implicaria uma relação de causa e efeito. Para Sartre (2014a, p. 700) não há diferença entre escolher e existir e o que ele entende como fundamental na realidade humana, são as escolhas livres e responsáveis, ações humanas, sejam elas quais forem, não podem reduzir-se a libido freudiana, a pulsões de morte, ou seja, a processos dinâmicos inconscientes provindos de um aparelho psíquico.

\section{REFERENCIAS:}

FREUD, S. Sigmund Freud: Obras Completas. Buenos Aires: Amorrortu Editores, 1996.

SARTRE, J-P. O ser e o nada. Petrópolis: ed. Vozes, 2014a.

Demais referências:

\footnotetext{
${ }^{3} \mathrm{O}$ conceito de escolha original, em Sartre, é muito importante para entender a realidade humana. Sartre (2014a, p. 574), afirma que embora seja a consciência que se temp oraliza é a escolha original que estende o tempo, fazendo com que ao escolher-se e nadificar-se a realidade humana faça com que o futuro venha anunciar o que ela é, no presente, conferindo um sentido ao passado. Por isso, para o autor liberdade, escolha, nadificação e temporalização constituem a mesma coisa. Para saber mais ler: IV Parte de O Ser e o Nada - Ter, Fazer e Ser. Capítulo I - "Ser e Fazer: A Liberdade". Cf. Sartre, 2014a, p. 574.
} 
FREUD, Sigmund. A Interpretação dos Sonhos. Tradução de Walderedo Ismael de Oliveira; Rio de Janeiro: Imago Ed., 2001.

"História de uma neurose infantil: ("O homem dos lobos”): Além do princípio de prazer e outros textos" (1917-1920) / Sigmund Freud; tradução Paulo César de Souza - São Paulo: Companhia das letras, 2010a.

. "Batem numa criança"; "História de uma neurose infantil: ("O homem dos lobos"): Além do princípio de prazer e outros textos” (1917-1920) / Sigmund Freud; tradução Paulo César de Souza - São Paulo: Companhia das letras, 2010c.

"O mal-estar na civilização, novas conferências introdutórias à psicanálise e outros textos" (1930/1936) / Sigmund Freud; tradução Paulo César de Souza - São Paulo: Companhia das letras, $2010 b$.

. "O problema econômico do masoquismo"; "O eu e o id, "autobiografia" e outros textos" (19231925) / Sigmund Freud; tradução Paulo César de Souza - São Paulo: Companhia das letras, 2011a.

. "O eu e o id, "autobiografia" e outros textos" (1923-1925) / Sigmund Freud; tradução Paulo César de Souza - São Paulo: Companhia das letras, 2011 b.

GARCIA-ROZA, L. Introdução à metapsicologia freudiana, v.3. Artigos de metapsicologia: narcisismo, pulsão, recalque, inconsciente. $7^{\mathrm{a}}$ ed. Rio de Janeiro: Jorge Zahar Ed., 1995.

Introdução à metapsicologia freudiana, v.2. A interpretação do sonho. $7^{\mathrm{a}}$ Edição. Rio de Janeiro. Jorge Zahar Editor, 2004.

A. Freud e o inconsciente. Rio de Janeiro: Jorge Zahar ed., 2000

HANNS, L. Dicionário comentado do alemão de Freud. Rio de janeiro: Imago Editora, 1996.

LAPLANCHE, J. e PONTALIS, J.B. Vocabulário de psicanálise. Tradução: Pedro Tamen. São Paulo: Martins Fontes, 2001.

SARTRE, J-P A transcendência do ego. Lisboa: Edições Colibri, 2013.

Esboço de uma Teoria das Emoções. Rio de Janeiro: Jorge Zahar Ed., 1965.

O Imaginário São Paulo: Ática, 1996.

O Existencialismo é um Humanismo. São Paulo: Abril Cultural, 1973. Coleção “Os pensadores”.

SOUZA, P. C. As palavras de Freud: vocabulário freudiano e suas versões. São Paulo: Companhia das Letras, 2010. 